\title{
The Efficiency of Small and Medium Enterprises in Albania
}

\author{
Bitila Shosha, PhD Candidate
}

\author{
Lecturer, "Aleksandër Moisiu" University, Business Faculty, Durres, Albania
}

Email: bitilashosha@yahoo.com

Doi:10.5901/ajis.2014.v3n3p295

\begin{abstract}
Albania is going through a process of major economic and social changes. Since this process has been broad and wideranging, a lot of studies have been focused on its problematic, and specifically the efficiency of small and medium enterprises (SMEs) as the economic development fostering units. In Albania, as well as in other developing countries, the SMEs have not been very efficient due to several problems linked with their financial situation, financing process, and profitability. As already known, developing countries lack financial resources, this in turn is due to non-functioning of financial markets. Therefore, one of the main objectives of this paper is to analyse the problems of SMEs in general in Albania, and the problems they face in finding financial resources and support. This paper will also attempt to measure the variables of profitability, financial situation and other variables in order to assess their effects on the efficiency of SMEs.
\end{abstract}

Keywords: SMEs, Profitability, Financial Situation, Financing Process.

The main purpose of this paper is to identify and then to underpin the existence of profitability as part SMEs effectiveness in Albania. The data of this study were processed through the quantitative and statistical methods. In this paper, the linear regression model is used to analyze the data collected. Based on the results of the linear regression model, the analysis continued trying to give an answer to the study basic questions.

The data are analyzed with the linear regression method and the hypothesis testing is done through the interpretation of the regression coefficients. A panel data collected from 125 questionnaires, including the surveys of small and medium enterprises in the city of Tirana. These data were assessed through the multiple regression equations.

\section{Selection and Description of Sample}

About 125 questionnaires were prepared for this study. The survey method was used to collect data from 125 small and medium enterprises operating in the city of Tirana.

The survey was conducted through direct contact with the respondents and while filling in the questionnaires. The respondents were free to ask additional explanation in order to give a more adequate response.

The samples were chosen randomly from a vast list of businesses. The survey was carried out by picking out randomly businesses and going personally there to meet the business manager. In the event the business manager was not present the questionnaire was not filled in for that business. The purposes of such practice was to have a real view of the businesses in Tirana

The area where the survey was conducted was chosen by taking into consideration these parameters: main streets, distribution of businesses, and population demography. In addition, the sample covered key economy sectors, which was respected by surveying heterogeneous sectors areas.

\subsection{Content of questionnaire}

General data:

Business age,

number of employees

business plan

$\rightarrow$ level of technology

cost of employee training

$\rightarrow$ costs of promotion

$\rightarrow$ profitability, as percept by the respondents, using the Likert Scale.

$\rightarrow$ access to financing, as percept by respondents, using the Likert Scale. 


\subsection{Collection and representation of data}

Data collected from the questionnaires were initially entered in an excel table. In the columns all questions responses were entered, corresponding to each part of the questionnaire, while the respondents were entered in the rows. The data contained in such Excel table served to design a series of graphics which give the current position of some selected main characteristics, compared by sectors. Their interpretation is given below. The data in this table were transported to e-view programme for a more detailed statistical processing. The results of such processing are also given below.

\subsection{Analysis of Data}

The multiple regression models were used to analyze the qualitative and quantitative data. The purpose of such analysis is to try to identify weather there is any correlation between the dependent variable- profitability which is an indicator of SMEs efficiency - and the other variables which affect on it. The results of the regression model are taken by the specific econometric software- e-view- then combined with other computer programs, in order to process data in order to generate an accurate results from the surveys carried out.

\section{Design of Model and Definition of Variables}

The research, in order to meet the primary objective of this paper, was initially based on the quantitative methods. At a second stage an econometric model was designed to identify and measure the factors primarily affecting the efficiency of SMEs.

Theoretically the multiple regression models are used to examine the correlations between the variables, in order to compare the significance of independent variables and estimate the dependent variables value.

The most adequate method to test such correlation is the linear function. Short (1979) argues that a linear function gives better results than any other function used. The specific test, according to Davidson, Godfrey and MacKinnon (1985) was also applied on the results which supported the use of linear function.

To test the hypotheses, based on the data collected, regarding the correlation between profitability and the determinant variables affecting thereto, the following linear model was used:

$Y=\alpha+\beta X+\varepsilon$
$\alpha=$ constant rate
$Y=$ SME profitability variable
$\mathrm{X}=\left(\mathrm{X}_{1}, \mathrm{X}_{2}, \mathrm{X}_{3} \ldots \mathrm{X}_{\mathrm{n}}\right.$, independent variables vector)(determinant)
$\beta=\left(\beta_{1}, \beta_{2}, \beta_{3} \beta_{4}, \beta_{5}\right.$ independent variables coefficient vector) (determinant)
$\varepsilon=$ error rate

This is the linear regression function equation which defines the correlation between variables taken in the study. Where $\alpha$ is the model constant rate and $\beta^{1}$ is the linear regression coefficient function. The value of function $t, \varepsilon$ in the linear regression is dependent on the coefficient $\beta, q, \varepsilon$ which means that if the coefficient $\beta$ is negative, and then the determinant or independent variable affects negatively on the dependant variable: an increase with one unit in the independent variable will reduce the dependent variable with the value of the respective coefficient.

Likewise, if the coefficient $\beta$ is positive, the dependant variable will increase with the value of the corresponding coefficient. $\boldsymbol{\alpha}$ is the constant value for which a dependant variable is predicted if the coefficients $\beta, t, \varepsilon$ of the independent variables $t, \varepsilon$ are equal to 0 (if $\beta_{1}=\beta_{2}=\beta_{n}=\ldots=0$ ) then $Y=\alpha$. In addition, $\varepsilon$ is the error rate which expresses the effect of all other variables, besides the dependent and independent variables considered in the regression function.

The regression model used in this study is the following:

In this linear regression model the number of independent variables is 5 . The equation is as follows:

$Y=\alpha+\beta_{1} X_{1}+\beta_{2} X_{2}+\beta_{3} X_{3}+\beta_{4} X_{4}+\beta_{5} X_{5}+\varepsilon$

By identifying the dependent variable and the independent variables, the following equation is designed:

RENTAB $=\alpha+\beta_{1}$ PLBIZNESI $+\beta_{2}$ PRODUKTIV $+\beta_{3} N R+\beta_{4}$ DT2 $+\beta_{5}$ DT2 $+\varepsilon$

In the table below, the elements studied with the linear regression are interpreted by identifying the standard model with the model elements under review.

${ }^{1} \beta$ - represents the contribution of each independent variable on the dependent variable estimation 


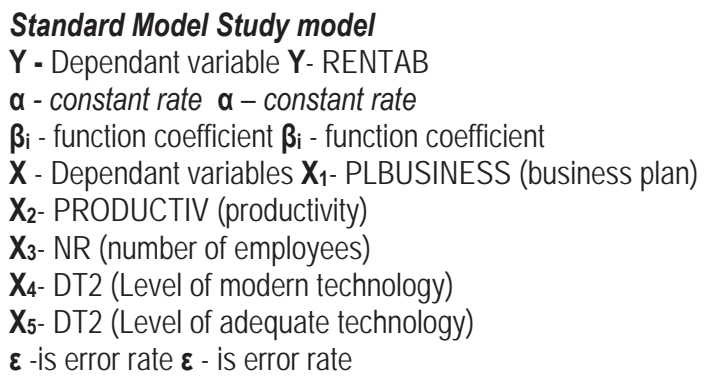

\section{Econometric Interpretation of Variables}

\subsection{Dependant variable (Profitability)}

One of the dependent variables, which are an important part of the SMEs efficiency, used in this study is profitability. The data were provided through direct interviewing of businesses entities by taking responses about 10 questions of the questionnaire: what do you think, how profitable is your activity? Answers from 0 (not at all) to 10 (fully).

Y- RENTAB (profitability determinant) - the rate of profitability according to the business entities perceptions.

\subsection{Independent variables}

Among all variables, the following five dependant variables were selected for this study:

1. $\mathbf{X}_{1}$ - PLBIZNESI (business plan)

2. $\mathbf{X}_{2}$ - PRODUKTIV (turnover/number of employees)

3. $X_{3}-\mathrm{NR}$ (number of employees)

4. $\mathbf{X}_{4}$ - DT2(level of modern technology)

5. $\mathbf{X}_{5}$ - DT2 (level of adequate technology)

\section{Constructing Statistical Hypothesis}

The statistical hypothesis for this research is the most important part of the work. It helps in giving responses to the main questions raised for the realization of the research aim. It addition, it helps in stating the conclusions reached.

$\mathrm{H}_{0}$ : None of the variables reviewed in this study does not have effect"

$\left(\beta_{1}=\beta_{2}=\beta_{3}=\beta_{4}=\beta_{5}=0\right)$

$\mathrm{H}_{1:}$ "At least one of the variables reviewed in this study has effect"

$\left(\beta_{1}=\beta_{2}=\beta_{3}=\beta_{4}=\beta_{5} \neq 0\right)$

In order to test the correlation between profitability (RENTAB), as the dependent variable and the explanatory variables, such as business plan ( $\mathbf{X}_{1}$ - PLBIZNESI), productivity ( $\mathbf{X}_{2}$-PRODUKTIV), number of employees $\left(\mathbf{X}_{3}\right.$-NR), level of modern technology $\left(\mathbf{X}_{\mathbf{4}}-\mathrm{DT} 2\right)$, level of adequate technology $\left(\mathbf{X}_{5}\right.$-DT3), and the following hypotheses are constructed:

$\mathrm{H}_{0}$ : "Profitability is not dependent from the presence of a business plan, productivity, number of employees, level of modern technology, nor the level of adequate technology" $\beta_{1}=\beta_{2}=\beta_{3}=\beta_{4}=\beta_{5}=0$

$\mathrm{H}_{1}$ : "Profitability is dependent from the presence of a business plan, productivity, number of employees, level of modern technology, and the level of adequate technology" At least one $\beta_{1}=\beta_{2}=\beta_{3} \beta_{4}=\beta_{5} \neq 0$

\section{Assessing and Testing of Statistical Data}

The statistical model was used to test and asses these data. It used the $r$-square method with a confidence level of $p=$ 
0.95 or significance level of 0:05 based on the results of the survey.

Choosing the most appropriate model to make the necessary analysis is based primarily on tests that measure the compatibility of the main model as:

$>$ F-statistics, to test the compatibility of the model,

$>T$-test, to test the significance of the variables correlation,

$>R$-squared, explanatory mean of the variation of profitability from the variables taken into consideration in this study model.

$>$ Other tests trying to prove the adequate form of correlation, the existence or not of multicollinearity.

\section{Econometric Model Results and their Interpretation}

The econometric model generated by the data analysis is given below:

RENTAB = 5.292986+0.645434 PLBIZNESI+5.37E-07 PRODUKTIV+0.188332 NR-0.594442 DT2-1.315143 DT3+

$\varepsilon$

The table given below indicates the regression output. There are reflected the values of $t$ and those values of $t$ that are larger than 2 or smaller than (-2), or greater than 2 in absolute value, are statistically significant coefficients while the rest are not statistically significant coefficients, significance level (0:05).

Based on the table, it is noticed that the most significant determinants in our model can be listed as below:

\section{Table No.1}

\begin{tabular}{|l|c|c|}
\hline \multicolumn{1}{|c|}{ Variable } & t-Statistic & Prob. \\
\hline NR & 3.366084 & 0.0011 \\
\hline PRODUKTIV & 3.182293 & 0.0019 \\
\hline DT3 & -2.793062 & 0.0062 \\
\hline DT2 & -2.338949 & 0.0212 \\
\hline PLBIZNESI & 2.129935 & 0.0355 \\
\hline
\end{tabular}

Source: Calculation of the author

The most significant determinant in our model is NR- the number of employees- which means that profitability is dependent on the number of employees.

In order to test the global importance of the model, the Fisher values are taken into consideration. It is noticed that Fisher value indicates that the model is in general statistically significant. Therefore, it is accepted $\boldsymbol{H}_{1}$ that there is at least one variable with $\neq 0$ coefficient.

$\mathrm{H}_{0}$ : "None of the variables taken into consideration do not affect on the SMEs profitability

$\beta 1=\beta 2=\beta 3=\beta 4=\beta 5=0$------- It is rejected $H_{0}$

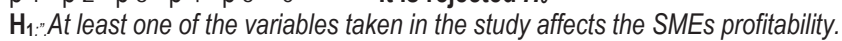

There is at least one $\beta 1=\beta 2=\beta 3 \beta 4=\beta 5 \neq 0$----------It is accepted $H_{1}$

Table No 2. Final results of the data testing

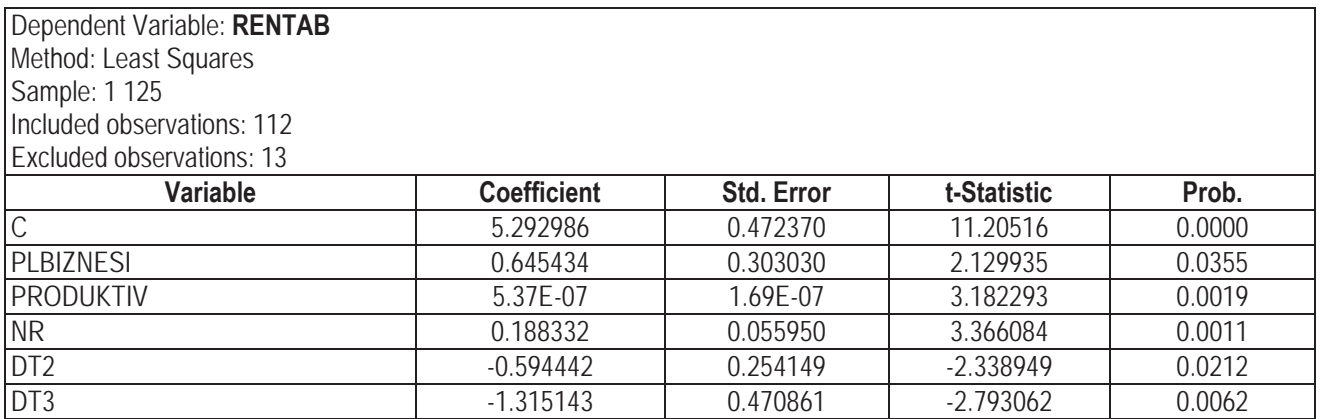




\begin{tabular}{|l|c|c|c|}
\hline R-squared & 0.298390 & Mean dependent var & 6.955357 \\
\hline Adjusted R-squared & 0.265296 & S.D. dependent var & 1.410312 \\
\hline S.E. of regression & 1.208848 & Akaike info criterion & 3.269295 \\
\hline Sum squared resid & 154.8991 & Schëarz criterion & 3.414929 \\
\hline Log likelihood & -177.0805 & F-statistic & 9.016230 \\
\hline Durbin-Watson stat & 1.900137 & Prob (F-statistic) & 0.000000 \\
\hline
\end{tabular}

Source: Calculation of the author

The $\mathrm{R}^{2}$ (the coefficient of determination) is 0.29839 , or simply $29.9 \%$, and it indicates that the variables taken in this study explain the regression model at 30\%. This figure shows that such variables are not the only ones, but there are also other factors having significance.

The adjusted $\mathrm{R}^{2}$ is 0.265296 which of course is slightly smaller than $\mathrm{R}^{2}$ (coefficient of determination). It indicates that there are other variables not yet included.

In addition, the DURBIN-WATSON value is 1.900137, thus approximately 2. This means that our model does not suffer from multicollinarity. This is a very good indicator showing that the independent variables are not correlated.

\section{Graphs Interpretation}

Other important elements of the data processing are the graphical interpretation and the analytical description of the data concerned.

Graph No. 1 Profitability, as per the presence or not of a business plan

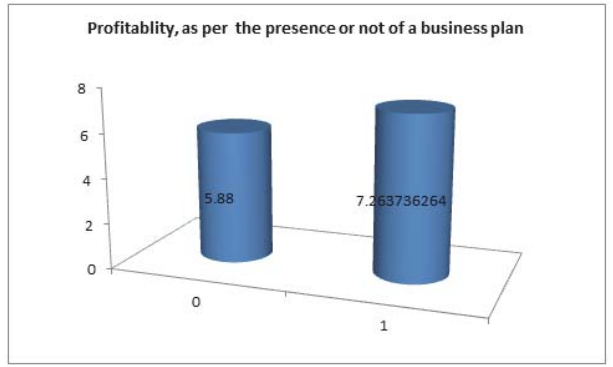

Source: Calculation of the author

From the profitability correlation graph and the existence or not of a business plan, it is evident that profitability, similar to what was indicated by the econometric model is dependent on the business plan. The existence of a business plan is significant on the efficiency of a company, such as the companies which carry their policies under a business plan. From the graph, it is evident that the companies not following a business plan have a level of 5.88,. While the rest having and following a business plan perform at 7.26 .

Graph No. 2 Profitability as per sectors

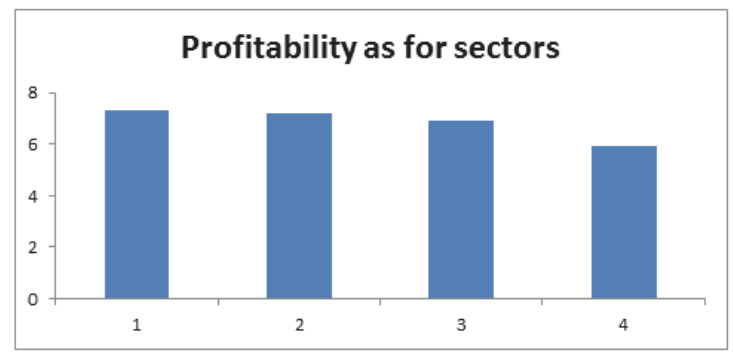

Source: Calculation of the author 
From the graph showing the correlation between profitability and the sectors, it is noticed that the manufacturing sector (1) generates the highest profitability, followed by the services sector (2), and then by the trade sector (3), and in the end the construction sector (4).

Graph No. 3 Access to financing as per sectors

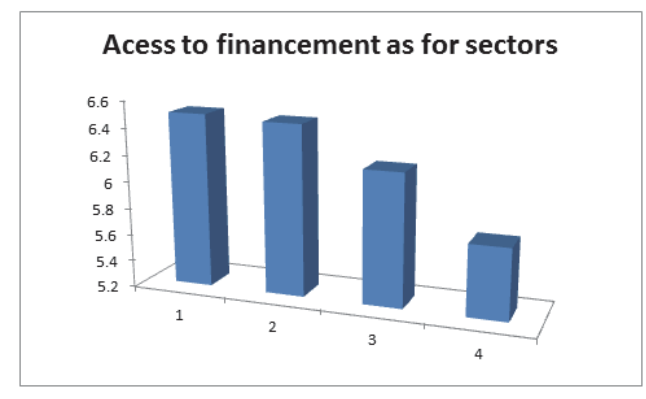

Source: Calculation of the author

From the graph showing the access to financing according to the sectors, it is noticed that the manufacturing sector has the highest access to financing. However, it is evident that all sectors have access to financing.

\section{References}

Becchetti, L. and Trovato, G., 2002. "The determinants of growth for small and medium sized firms: the role of the availability of external finance". Small Business Economics,

David J Storey,1994,Understanding the Small Business Sector, London: Routledge,

David S. Evans, "The relationship between firm growth, size and age: estimates for 100 manufacturing industries". The Journal of Industrial Economics, 1987;

Davidsson, P. , Delmar, F. Wiklund, J. ,2006, "Entrepreneurship and Growth of firms";

Davidsson, P. and Wiklund, J., 2000. "Conceptual and empirical challenges in the study of firm growth" in: D. Sexton and H. Landstrwm, eds. The Blackwell handbook of entrepreneurship. Oxford: Blackwell;

Freel, M. S. and Robson, P. J. A., 2004. "Small firm innovation, growth and performance". International Small Business Journal;

Hausman, J. A., 1978. "Specification tests in econometrics". Econometrica,

Heshmati, A. 2001. "On the growth of micro and small firms: evidence from Sweden". Small Business Economics;

Myslym Osmani, 2010, Econometrics (with applications);

Ozkan, A., and Ozkan, N., 2004. "Corporate cash holdings: an empirical investigation of UK companies". Journal of Banking and Finance,

Wiklund, J., Patzel, H. and Shepherd, D. A., 2009. "Building an integrative model of small business growth". Small Business Economics; 